\title{
ANÁlise dAS PERCEPÇõeS E DESEMPENHOS DISCENTES COM A UTILIZAÇÃO DO SOFTWARE R EM UMA DISCIPLINA DE GRADUAÇÃO DE NATUREZA MULTICURSO
}

\author{
ANALYSIS OF STUDENT PERCEPTIONS AND PERFORMANCE USING THE \\ SOFTWARE R IN A MULTI-PROGRAM UNDERGRADUATE COURSE
}

DOI: 10.23926/RPD.2526-2149.2020.v5.n3.p1568-1592.id886

\section{Leandro Blass \\ Doutor em Modelagem \\ Computacional (UERJ) \\ Professor na Universidade \\ Federal do Pampa \\ (UNIPAMPA) \\ leandroblass@unipampa.edu. $\underline{b r}$}

\section{Guilherme Goergen \\ Doutor em Meteorologia}

(UFSM)

Professor na Universidade

Federal do Pampa

(UNIPAMPA)

guilhermegoergen@unipamp

a.edu.br

\section{Valesca Brasil Irala}

Pós-Doutorado Doutorado

em Letras - Linguística

Aplicada (UCPel)

Professora na Universidade

Federal do Pampa

(UNIPAMPA)

valescairala@unipampa.edu. $\underline{b r}$
Resumo: A tomada de decisão em relação às mudanças necessárias no Ensino Superior perpassa necessariamente pela valorização do engajamento consultivo dos discentes. Nesse sentido, este trabalho tem como objetivo analisar as percepções discentes no início e no final de um semestre letivo, em uma disciplina multicurso de Cálculo Numérico, ofertada em uma universidade pública no sul do Brasil e, também, observar os desempenhos discentes nesse contexto. Os dados foram gerados a partir de questionários aplicados no início e no final do semestre, além dos resultados do desempenho final dos estudantes. O desenho metodológico é misto, sendo qualitativo para compreensão dos dados contextuais e quantitativo para as inferências estatísticas analisadas no software R. Conclui-se que o desenvolvimento de instrumentos para qualificar o engajamento consultivo de discentes é uma tarefa complexa, porém necessária para o acompanhamento longitudinal e comparativo de mudanças educacionais implementadas no interior das diversas disciplinas ofertadas na instituição analisada.

Palavras-chave: Cálculo Numérico. Engajamento Discente. Questionário.

\begin{abstract}
Decision-making in relation to the mandatory changes in Higher Education involves valuing the student's consultative engagement. In this sense, this work aims to analyze student perceptions at the beginning and at the end of an academic semester, in a Numerical Analysis course offered for differents undergraduate programs at a public university in Southern Brazil, and also observe student performances in this context. The data were generated from surveys applied at the beginning and the end of the semester, in addition to the student's performance results. The methodological design is mixed, being qualitative for understanding the context and Quantitative data for the statistical inferences analyzed in software $\mathrm{R}$. It is concluded that the development of instruments to qualify the consultative engagement of students is a complex task, however necessary for longitudinal monitoring and comparative of educacional changes implemented within the various courses offered in the analyzed institution.
\end{abstract}

Keywords: Numerical Analysis. Consultative Engagement. Survey 


\section{CONSIDERAÇÕES INICIAIS}

O ensino superior, apesar da vertiginosa expansão mundial nas últimas décadas, também tem sido marcado por evidentes contradições (McCOWAN, 2019), que vão desde os sentidos atribuídos ao seu papel na atualidade, até uma atenção às macro e micropolíticas que incidem sobre as problemáticas relacionadas ao acesso, à permanência, à evasão e a conclusão dos estudantes nos cursos em que ingressam. Tais problemáticas abarcam um conjunto de fenômenos de natureza complexa e multifacetada (TINTO, 2012; ACEVEDO, 2020).

Muitos esforços têm sido empreendidos na tentativa de demarcar mudanças efetivas nos objetivos educacionais e no perfil dos profissionais a serem formados, resultando em uma constante revisão nas metodologias de ensino (BACICH; MORAN, 2018; TALBERT, 2019) e no formato das práticas avaliativas sobre os desempenhos discentes (CARLESS et al., 2017; MOROSINI et al., 2016), como forma de demarcar ações institucionais de impacto sobre as problemáticas apresentadas (MORAES; HEIDEMANN; ESPINOSA, 2020). Considerando esse cenário, este artigo é parte constitutiva de um caminho teórico-metodológico em processo, levado a cabo no projeto de pesquisa "Aprendizagens ativas e colaborativas: análise da percepção docente, do engajamento discente, da autorregulação e do processo avaliativo", vinculado ao Grupo de Pesquisa sobre Aprendizagens, Metodologias e Avaliação - GAMA (cadastrado no Diretório de Grupos de Pesquisa do CNPq). Temos como pressuposto a busca pela inovação educativa (CARBONELL, 2002), a partir da promoção de aprendizagens situadas e co-construídas, as quais visam um processo de participação ativa e crítica dos diversos agentes envolvidos (SALVAT, 2008).

Tendo essa compreensão como premissa, advogamos que o engajamento consultivo ${ }^{1}$ (BOLS, 2020) proporcionado aos estudantes é um potente (embora não exclusivo) passo para oportunizar esse processo de participação, na medida em que tanto o planejamento docente imediato/futuro (considerado como uma micropolítica de sala de aula) quanto as políticas curriculares mais amplas, desenvolvidas pelos diferentes cursos ofertados em uma instituição, podem valer-se analiticamente de dados gerados nesse âmbito micro para desenvolver ações inovadoras, de forma situada, tal como advogam Bohn (2001) e Dornelles (2008).

O pensamento e a prática situados relevam a necessidade de tomada de decisões locais, pautadas nas demandas e problemáticas nascidas em um cenário específico e orientadas à construção de respostas criativas, críticas e embasadas teoricamente, as quais não apenas

\footnotetext{
${ }^{1}$ A definição de engajamento consultivo é apresentada na próxima seção, voltada aos conceitos teóricos mobilizados na pesquisa.
} 
possam vir a contribuir para mudanças de natureza empírica, mas igualmente para a criação de novas concepções teóricas (e metodológicas) coerentes e adaptáveis ao contexto de ensino a que se vinculam.

Compreendemos que, ao contemplar as percepções (INGOLD, 2010) dos alunos perante o seu processo formativo, estamos não apenas gerando dados de pesquisa sobre o ensino e a aprendizagem, mas também possibilitando-lhes caminhos para refletir sobre suas percepções pré-existentes, e, assim, contribuindo para monitorá-las e/ou modificá-las ao longo do percurso (e, de forma bidirecional, também produzindo esses efeitos sobre os docentes). Buscamos encontrar possibilidades mais produtivas para a geração de dados dessa natureza, bem como sobre a tomada de decisão e formas de socialização desses dados, para que se tornem úteis na construção de uma cultura reflexiva no contexto de ensino analisado, que possa ser, a médio prazo, estendida também a um número mais expressivo de atores institucionais, a partir das contribuições alavancadas no âmbito do grupo de pesquisa a que estamos vinculados.

Dito isso, apontamos como objetivo deste texto analisar as percepções discentes no início e no final de um semestre letivo, em uma disciplina de graduação de natureza multicurso (IRALA et al., 2020), vinculada à área da Matemática (Cálculo Numérico), visando promover o engajamento consultivo dos alunos frente à compreensão que têm sobre a sua prática discente no processo educativo da disciplina em análise, sobre a prática docente e sobre as práticas docente-discentes, em interrelação, estabelecendo, por fim, um paralelo com o desempenho discente ao término do semestre, contrapondo-o à motivação inicial autopercebida e ao empenho final autopercebido.

Na próxima seção, apresentamos uma breve discussão teórica a respeito dos conceitos mais relevantes para o desenvolvimento da pesquisa. Na sequência, estabelecemos o aparato metodológico e, após, a análise dos resultados, pautada na utilização do software R, entendido como uma ferramenta útil e vantajosa para o agrupamento de dados educacionais, tais como os aqui apresentados. De acordo com Prokop e Wininger (2018), o R é uma das linguagens de programação mais populares e bem classificadas para a realização de análises estatísticas. Outra vantagem apontada em relação a softwares similares é que ele é de código aberto, de forma a permitir que qualquer usuário possa contribuir para aprimorá-lo. Isso de fato ocorre por parte da comunidade que o utiliza, classificada pelos autores como bastante atuante, por compartilhar com frequência novas funcionalidades à ferramenta. 


\section{PRINCIPAIS CONCEITOS TEÓRICOS MOBILIZADOS}

O processo didático, compreendido em uma perspectiva sociocultural, requer "formas de participação oportunas, apropriadas e antecipatórias" (TOBIN, 2012, p. 03), devendo ser pautado pela promoção de perspectivas coletivas em detrimento das individuais. Como isso, é preciso que docentes possam introduzir uma maior horizontalidade na tomada de decisões sobre a sua organização, (re)organização e dinâmicas próprias. Já em uma visão mais tradicional sobre esse processo caberia apenas ao professor refletir e distribuir as pautas que regem as "regras do jogo". Entretanto, conceber tais mudanças também exige um planejamento sobre como podem ser geradas estratégias que possam contribuir para uma condução orgânica e produtiva da horizontalidade por nós defendida.

Em nossa perspectiva, entendemos que buscar compreender e captar as percepções dos estudantes sobre si mesmos, sobre a complementaridade relacional dos papéis docente-discente e sobre o que compete prioritariamente ao docente (entendido como um interlocutor mais experiente nos objetos do conhecimento mobilizados) pode contribuir para gerar estratégias coletivas que possam ser mais produtivas para o processo didático empreendido, partindo das percepções pré-existentes (de forma a serem, dependendo dos resultados, reforçadas e/ou confrontadas pela ação didática). Espera-se, como efeito final, o sucesso acadêmico dos alunos (TINTO, 2012) e, por outro lado, trazer elementos empíricos que ajudem a contribuir para o desenvolvimento profissional docente, em uma perspectiva crítica e reflexiva, pautando suas ações de acordo com as condições do contexto (RAMOS-RODRÍGUEZ; MARTÍNEZ, PONTE, 2017).

Entendemos que um indicador humanista de sucesso acadêmico deve incidir tanto sobre resultados quantitativos (por exemplo, diminuição no número de reprovações e desistências, promoção de desempenhos acadêmicos mais elevados), quanto em aspectos qualitativos, ou seja, pautados por princípios experencialistas, tais como "busca por uma vida satisfatória, ser humano como criador, o saber como multidimensional, o conhecimento como intersubjetivo, a educação como intrínseca ao sujeito e a democracia como participação" (AUBUSSON; SCHUCK, 2008, p. 6).

Ao nos alicerçarmos nesses princípios, podemos advogar que o conceito de sucesso acadêmico não deve estar vinculado unicamente ao desenvolvimento intelectual (muitas vezes traduzido de forma restrita ao alcance de uma nota minimamente esperada ao final do semestre - a curto prazo) ou à obtenção do diploma (a médio prazo), mas também ao que se conhece como bem-estar acadêmico (RODRÍGUEZ et al., 2020), compreendido, em uma visão 
holística, como um leque que abarca inúmeros atributos, tais como os relacionados às atitudes, às motivações, à compreensão sobre a importância de determinados conhecimentos para a própria formação (e para a vida em si, a longo prazo), à satisfação ou insatisfação com resultados prévios, à valorização e compreensão sobre a dinâmica dos processos de ensino e de suas próprias estratégias postas em cena nesse jogo didático, entre outros. Ainda, estamos de acordo com Picton, Kahu e Nelson (2018, p.3), pois o sucesso "acontece todos os dias na universidade", ou seja, ele é de natureza processual e não um resultado acabado e imutável na vida humana.

Essa complexa trama, que envolve condicionantes individuais e coletivos, pode ser interpretada pelo viés das percepções dos sujeitos frente às suas vivências acadêmicas. Diferentes áreas do conhecimento (Psicologia, Neurociências, Filosofia, etc.) têm se valido tradicionalmente do conceito de percepção como uma via de acesso à organização das experiências sensoriais, outorgando-lhe um papel importante para o desenvolvimento complexo da aprendizagem humana (AFFOLTER, 1981; STEIL; CARVALHO, 2012; OLIVEIRA; MOURÃO-JÚNIOR, 2012). Entretanto, nos modelos mais clássicos a respeito de como se configura a percepção humana, afirma-se categoricamente que ela "não pode ser observada de forma direta" (AFFOLTER, 1981, p.4).

Diferente dos modelos clássicos advindos da Psicologia, o antropólogo britânico Tim Ingold (2000) compreende a percepção pautada na indissociabilidade entre mente e corpo, negando-a como supostamente sendo uma operação mental pré-existente à ação, mas sim considerando-a como uma forma de ação. Nesse sentido, quando proporcionamos o engajamento consultivo aos alunos a respeito de suas percepções, ou seja, o que Bols (2020, p. 72) entende como "oportunidades de prover aos estudantes formas de expressar opiniões individuais, perspectivas, experiências, ideias e preocupações", não estamos apenas levantando dados para uma tomada de decisão futura, mas ensejando que essa tarefa per se contribua também para que esse sujeito possa atuar e refletir sobre sua condição de aluno, na interação com a condição docente, com a condição de outros (seus colegas) e, também, frente à diversidade de artefatos à disposição no seu ambiente de aprendizagem (CZAPLINSKI, 2020).

Sem esgotar nesta seção o campo teórico mobilizado, discorreremos na seção seguinte sobre os procedimentos metodológicos e sobre a contextualização da disciplina em que a pesquisa se desenvolveu. Na sequência, a partir dos dados visualizados, retomaremos aspectos teóricos relevantes para dialogar com o conjunto dos resultados encontrados. 


\section{Percurso metodológico}

A pesquisa educacional reconhece há bastante tempo o termo "investigação coprodutiva" (GREENWOOD; LEVIN, 2006, p. 102), a qual está baseada "na cooperação profissional entre o pesquisador e o colaborador". No caso da pesquisa em foco, valemo-nos do que na literatura internacional se entende como self-study com a estratégia do critical friends (CORNEJO, 2016; SANDRETTO, 2016; SCHUCK; RUSSELL, 2016; BUTLER et al., 2011), ou seja, um docente abre espaço para o desenvolvimento da pesquisa em sua própria sala de aula, construindo, em conjunto com os demais pares pesquisadores, novos olhares para os desafios da docência e para o desenho da pesquisa levada a cabo, a partir de pautas e focos préestabelecidos conjuntamente e em constante reavaliação. Torna-se, assim, tanto colaborador quanto pesquisador da pesquisa em tela, assumindo a condição de insider (GREENWOOD; LEVIN, 2006), o que vem nos permitindo produzir uma visão mais contextualizada do processo didático, com as suas nuances e complexidades constitutivas.

A pesquisa que se desenvolve com foco no processo didático e, no caso desta pesquisa, com ênfase nas percepções discentes no âmbito de uma disciplina em específico, não deve negligenciar que a flutuação no número de participantes ao longo da geração dos dados é inerente ao cenário típico de qualquer sala de aula e esse é um aspecto incontornável na pesquisa educacional (ou, mais amplamente, em qualquer pesquisa com seres humanos que não se restrinja a uma geração pontual dos dados). Ressaltamos que utilizamos propositalmente o termo geração de dados em vez de coleta de dados, pois é o termo indicado quando se assume um olhar situado para compreender os fenômenos propostos. Assumimos também que adotamos uma perspectiva metodológica mista, na qual se desenha uma abordagem tanto quantitativa quanto qualitativa para interpretação dos resultados (BLAXTER; HUGHES; TIGHT, 2005).

As fontes de dados tomadas para responder aos propósitos dos artigos foram duas: a) dados primários - dois questionários (administrados em dois momentos diferentes do semestre letivo - o primeiro, ao início das aulas e o segundo, depois do término de todas as atividades acadêmicas previstas durante o semestre) e b) dados secundários - registros acadêmicos fornecidos pelo docente ministrante (que, por sua vez, é um dos autores do texto), após o encerramento das aulas, concluídas em dezembro de 2019.

Para a geração dos dados primários, em cada um dos momentos previstos (início e fim), os discentes foram convidados a participar da pesquisa de forma livre e voluntária, consentindo, para cada etapa, a sua participação por meio do Termo de Consentimento Livre e Esclarecido 
(TCLE) online, enviado juntamente com os respectivos questionários produzidos para analisar as percepções discentes. Assim, alertamos para a divergência no número de participantes em cada momento do semestre, bem como em relação à análise dos desempenhos e critério de exclusão para contrastar motivação inicial autopercebida, empenho autopercebido ao término do semestre e desempenho final na disciplina analisada a partir dos relatórios fornecidos pelo docente. Optamos por detalhar a flutuação no número de participantes por etapa, ao longo do texto.

O estudo foi realizado em uma Universidade Federal de Ensino Superior localizada no interior do Rio Grande do Sul (RS), em duas turmas de natureza multicurso (IRALA et al., 2020), na disciplina de Cálculo Numérico, compostas por um total de sessenta e quatro alunos, oriundos dos seguintes cursos: Engenharia Química (EQ), Engenharia de Alimentos (EA), Engenharia de Energias (EE), Engenharia da Computação (EC), Engenharia de Produção (EP) e Licenciatura Matemática (LM). Com relação à faixa etária, 69,6\% dos estudantes tinha entre 20 e 25 anos; 21,7\%, entre 26 e 30 anos; 4,3\% entre 31 e 40 anos e, por último, 4,3\% possuíam mais de 41 anos. Em relação à quantidade de vezes que já havia cursado o componente, 67,4\% estava cursando-o pela primeira vez; $30,4 \%$ pela segunda vez e $2,2 \%$ pela terceira vez.

O objetivo do docente, ao longo de vários semestres em que é responsável pela referida disciplina, é promover o uso de Cálculo Numérico para resolver, analisar e explorar aplicações que se aproximem dos campos profissionais dos cursos envolvidos, através de variadas estratégias didáticas (FERRARI; SÁENZ, 2018) em sala de aula e fora dela, com práticas avaliativas orientadas à aprendizagem (CARLESS et al., 2017) através do uso de rubricas (FRANCIS, 2018) e o fomento do engajamento interativo (BARROS et al., 2004). Também, com a utilização do Ambiente Virtual de Aprendizagem (AVA) Moodle para mobilizar alguns princípios propostos pelo modelo de sala de aula invertida (TALBERT, 2019). O conjunto desses aspectos são o ponto de partida para a construção dos instrumentos desenvolvidos especificamente para o contexto da disciplina em questão.

Na primeira aula, foi explicitada aos alunos a intenção da realização da pesquisa e o convite espontâneo à colaboração. Logo na sequência, os discentes participantes responderam ao questionário inicial disponibilizado via Plataforma Google Forms. Nessa etapa, foram alcançados um total de quarenta e seis respondentes. Ressalta-se que, como as perguntas abertas não são de preenchimento obrigatório, há poucos registros de respostas nesse formato. Já no questionário final, aplicado após a conclusão do semestre, um total de cinquenta e três discentes 
contribuíram com a geração dos dados e um número maior de alunos respondeu à única questão aberta proposta, que versava sobre sugestões para os semestres seguintes.

Os dados relacionados às questões de escala Likert foram tratados no software $\mathrm{R}(\mathrm{R}$ CORE TEAM, 2019), bem como a pergunta sobre motivação autopercebida do questionário inicial e a pergunta sobre empenho autopercebido no questionário final, além dos dados extraídos dos desempenhos finais dos discentes na disciplina foco. As demais perguntas (abertas, fechadas e contextuais) ajudaram, de forma complementar, a compor o processo interpretativo da análise, bem como a observação docente, em alinhamento à perspectiva situada e de cunho qualitativo que advogamos. A Figura 1 representa uma síntese do que denominamos “Arquitetura dos Questionários" e a caracterização das questões em ambas as etapas.

Figura 1 - Arquitetura dos questionário

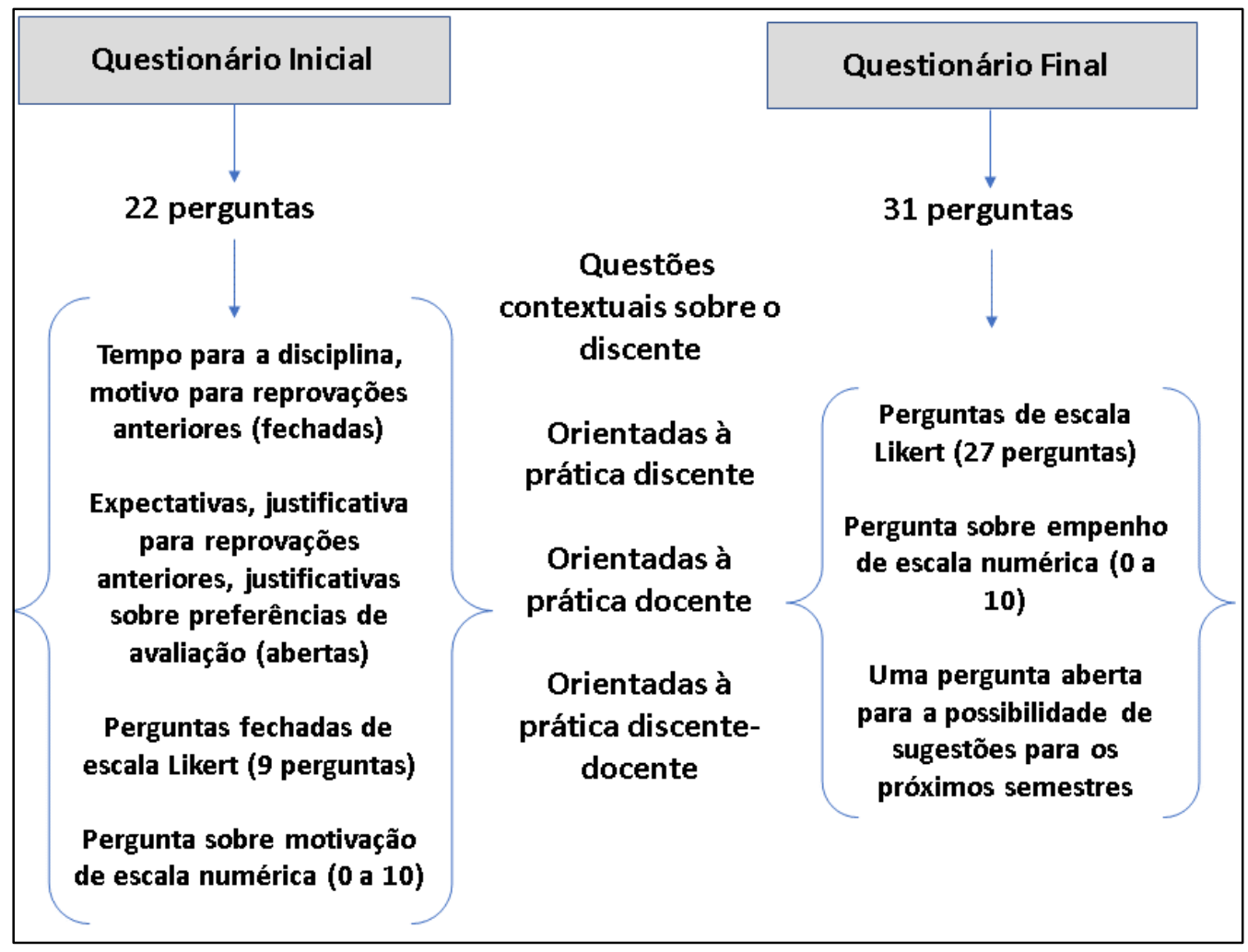

Fonte: Autores, 2020.

A escala Likert adotada foi a de cinco níveis, ou seja: concordo fortemente, concordo, não concordo e nem discordo, discordo e discordo fortemente. A escolha do número de itens foi ancorada em Dalmoro e Vieira (2013). Os autores compararam escalas Likert de três, cinco e sete itens. Os resultados desses autores apontaram que a escala de três pontos é a menos confiável, já a escala de cinco pontos teve, em média, a mesma precisão comparada com a 
escala de sete itens; porém, a escala de cinco itens mostrou-se mais fácil e mais veloz na análise dos dados, evidenciando ser a mais adequada, por isso a escolhemos.

Feijó et al. (2020) defendem a importância de, no uso de escalas Likert, os pesquisadores manipularem e apresentarem as informações de forma clara. Nesse sentido, consideramos a produtividade do uso do software R como eficiente para a visualização gráfica de dados dessa natureza, como um potente auxiliar para a interpretação dos resultados, bem como para a sua difusão a diferentes audiências (DALLA VALLE et al., 2018).

Entre as diversas bibliotecas disponíveis no $\mathrm{R}$, utilizamos o pacote ggpubr (KASSAMBARA, 2017) e a coleção de pacotes tidyverse (WICKHAM et al., 2019) para a manipulação e filtragem dos dados, cálculo das estatísticas e geração dos gráficos, bem como o pacote Likert (BRYER; SPEERSCHNEIDER, 2016) para a sintetização e visualização qualitativa das respostas da escala Likert.

Em relação ao desempenho discente, calculamos o intervalo interquartil (IQR), como a diferença entre o quartil superior (Q3) e o quartil inferior (Q1). Essa medida, juntamente com o valor da mediana, é particularmente útil para entender a dispersão do conjunto de dados (não simétricos) explorado neste trabalho. Os demais índices estatísticos seguem as metodologias tradicionais (DEVORE, 2018). Ainda, para cada um dos questionários, estimamos a consistência interna das questões de escala Likert através do uso do coeficiente Alfa de Cronbach $^{2}$ (CRONBACH, 1951). Feito o detalhamento metodológico, na seção seguinte, apresentaremos a análise dos resultados.

\section{Resultados E Discussões}

Os resultados serão apresentados nesta seção a partir de três enfoques: a) dados de Escala Likert no questionário inicial; b) dados de Escala Likert no questionário final e c) desempenhos finais, motivação inicial autopercebida e empenho final autopercebido.

\subsection{RESULTADOS REFERENTES AO QUESTIONÁRIO INICIAL}

A Tabela 1 apresenta os resultados do teste de confiabilidade do Alfa de Cronbach para as questões da escala Likert do questionário inicial. Foram consideradas as questões fechadas

\footnotetext{
${ }^{2}$ Voltado a avaliar à homogeneidade de um instrumento, ou seja, o quanto os itens agrupados são capazes de medir um mesmo domínio. Não há unanimidade na literatura em relação à melhor forma de interpretá-lo (MATTHIENSEN, 2011); porém, quanto mais próximos de 1 forem os valores, maior será considerada a consistência interna de um instrumento. Valores acima de 0,70 apontam para melhores resultados, mas próximos a 0,60 podem ser considerados como moderados, porém minimamente aceitáveis (SOUZA; ALEXANDRE; GUIRALDELLO, 2017).
} 
orientadas à prática discente (rótulo adotado: DIS_F) e à prática discente-docente (rótulo adotado: DD_F), pois havia, nesse questionário, apenas uma questão de escala Likert relacionada à prática docente (rótulo adotado: DOC_F); portanto, não foi possível agrupá-la para efetuar a análise dessa categoria.

Tabela 1 - Resultados do Alfa de Cronbach para o Questionário Inicial

\begin{tabular}{lccc}
\hline Categorias & Número de questões & Alfa de Cronbach & $\begin{array}{c}\text { Classificação } \\
\text { de resultado }\end{array}$ \\
\hline DIS_F & 5 & 0,59 & Moderado \\
DD_F & 3 & 0,52 & Moderado \\
\hline
\end{tabular}

Fonte: Autores, 2020.

A classificação dos resultados do Alfa de Cronbach foi considerada por nós como moderada, com base na literatura da área, o que pode ser interpretado em razão da pequena quantidade de itens por domínio (SOUZA; ALEXANDRE; GUIRALDELLO, 2017). A Figura 2 representa os dados dos respondentes ao questionário inicial, agrupados pela natureza da questão.

Figura 2 - - Resultados do questionário inicial

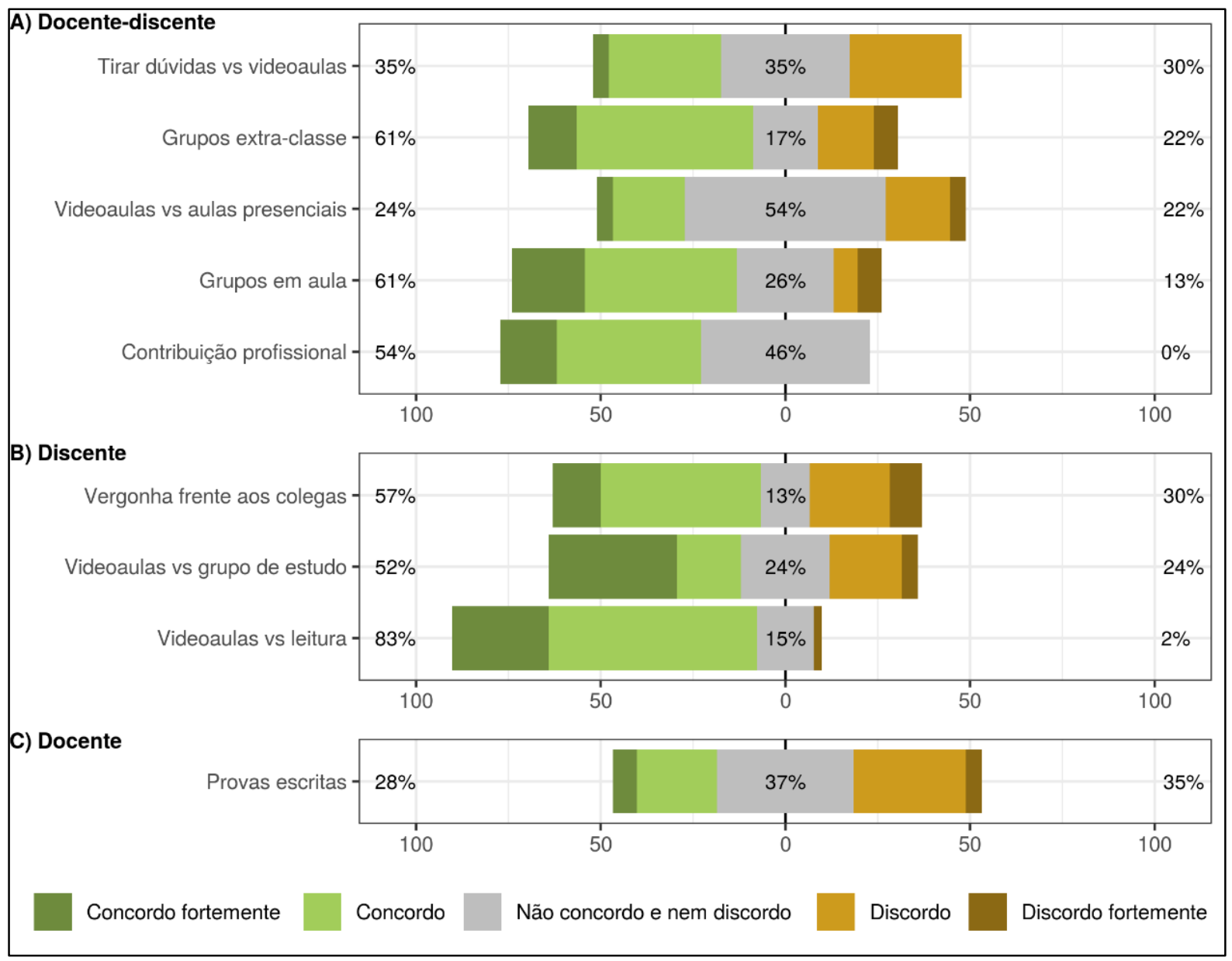

Fonte: Autores, 2020. 
As questões que nortearam os questionários foram segmentadas em categorias apenas para fins didáticos. Elas indicam uma orientação da prática mobilizada de forma prioritariamente unidirecional (quando tratamos das categorias "discente" ou "docente" de forma separada) ou bidirecional (quando entendemos que o êxito dessa prática é prioritariamente derivada dos papéis desempenhados por ambos), tendo como eixo central a busca pela compreensão da percepção dos discentes em relação a elementos que, ao longo do semestre, estão presentes nos diferentes ambientes de aprendizagem (CZAPLINSKI, 2020) vivenciados em Cálculo Numérico.

$\mathrm{Na}$ disciplina, são requeridas tarefas acadêmicas que demandam o contato com objetos de ensino (ZANI; BUENO; DOLZ, 2020) como as videoaulas produzidas pelo próprio docente em relação a cada tópico e os livros-texto disponíveis como referência da área. Também, um conjunto de atividades que se dão em sala de aula e fora dela, as quais requerem o engajamento interativo dos alunos com o docente e com os pares (BARROS et al., 2004). Sobre esse aspecto, destacamos que chama a atenção o alto índice de alunos que revelava ao início do semestre ter vergonha de fazer perguntas em aula perante os colegas (57\%). Entendemos que, embora haja uma boa aceitação de atividades em aula desenvolvidas em grupo (61\%), o processo interacional em sala de aula pode ser qualificado quando os discentes não apresentam esse tipo de barreira, ainda identificada como significativa.

Destacamos o alto percentual, $54 \%$, de discentes que se mostraram indecisos sobre a pergunta "Em geral, aprendo mais vendo videoaulas do que em aulas presenciais". Quando selecionamos somente os respondentes que foram aprovados na disciplina ao término do semestre, esse percentual subiu para 63\%. De maneira exploratória, destacamos que esses resultados convergem para o de outras pesquisas já realizadas a respeito, seja sobre o crescimento, entre os estudantes da atualidade, dos chamados ambientes pessoais de aprendizagem (CZAPLINSKI, 2020), que incluem, por exemplo, as redes sociais, bem como pelo fenômeno conhecido como Youtubologia e suas potencialidades para o processo cognitivo, especialmente pelos benefícios da combinação de formatos multimídias (THEES, 2019). Como aponta a autora, na última década, cada vez há mais pessoas recorrendo aos canais voltados aos conteúdos matemáticos disponíveis nessa plataforma como substitutivos ou como complementares aos modelos formais de ensino.

Outro aspecto que chama a atenção nos dados é a elevada proporção de alunos a qual considera que aprende mais vendo videoaulas do que lendo o livro-texto da disciplina. A soma entre os que concordam ou concordam fortemente com essa afirmativa é de $83 \%$, frente a 
apenas $2 \%$ dos que discordam fortemente. Sobre esse aspecto, entendemos o desafio das instituições de ensino, de forma geral, e dos docentes, de forma particular, em, cada vez mais, compreenderem as expectativas discentes no que diz respeito ao acesso aos recursos didáticos por meios digitais, seguindo a lógica 24/7, ou seja, vinte e quatro horas por dia e sete dias por semana (HARVEY; ANDERSON, 2020). Tais demandas têm requerido a criação de soluções inovadoras para atender a um perfil de aluno do ensino superior que, cada vez menos, tem se adaptado à utilização de artefatos convencionais utilizados nas formações de nível superior, tais como os tradicionais livros-texto (especialmente em seu formato impresso e, por consequência, sem poder dispor de nenhum conteúdo com recursos de multimídia ou mesmo com algum grau de interatividade).

Ainda em relação às videoaulas, identifica-se que $52 \%$ dos alunos as preferem em relação ao grupo de estudos extraclasse com colegas e que há indícios de equilíbrio em relação à preferência por videoaulas e a possibilidade de tirar dúvidas com o professor fora do horário de aula (35\% preferem tirar dúvidas com professor às videoaulas, 35\% mostraram-se em dúvida em relação a um aspecto sobrepor-se sobre o outro e $30 \%$ discordaram, ou seja, preferem videoaulas do que tirar dúvidas presencialmente). Esses dados coincidem com uma pesquisa prévia, de natureza exploratória, realizada em nosso grupo de pesquisa junto aos estudantes matriculados no componente curricular de Equações Diferenciais (SOARES et al., 2018). Ainda, a tendência tem sido revelada em outras gerações de dados que ainda não foram publicados pelo nosso grupo de pesquisa, mas que apontam para o mesmo caminho.

Também, destacamos a baixa preferência dos discentes por provas escritas (28\%) em detrimento de outros instrumentos e dispositivos avaliativos. Esse dado demonstra que os discentes mostravam-se abertos a práticas avaliativas inovadoras (CARLESS et al., 2017), como foi efetivamente proposto na disciplina, por meio de atividades de resolução de problemas em sala de aula e pela introdução de um conjunto de quatro rubricas (FRANCIS, 2018) para avaliação do processo de desenvolvimento de um trabalho colaborativo produzido em quatro etapas, seguindo o modelo da pesquisa científica, voltado à proposição de um problema formulado pelos próprios alunos, no qual os discentes tinham como orientação a busca por associar os conteúdos de Cálculo Numérico com as problemáticas vinculadas aos seus cursos de origem (BLASS; IRALA, 2020). 


\subsection{RESULTADOS REFERENTES AO QUESTIONÁRIO FINAL}

A Tabela 2 apresenta os resultados do teste de confiabilidade do Alfa de Cronbach, para as questões da escala Likert do questionário final.

Tabela 2 - Resultados do Alfa de Cronbach para Questionário Final

\begin{tabular}{lccc}
\hline Categorias & Número de questões & Alfa de Cronbach & $\begin{array}{c}\text { Classificação } \\
\text { de resultado }\end{array}$ \\
\hline DIS_F & 16 & 0,63 & Moderado \\
DD_F & 4 & 0,68 & Moderado \\
DOC_F & 7 & 0,71 & Bom \\
\hline
\end{tabular}

Fonte: Autores, 2020

Os resultados demonstram que o questionário final atingiu índices de confiabilidade mais favoráveis do que o questionário inicial. Esse resultado pode ter sido alavancado pelo número maior de itens apresentados em relação ao primeiro.

A Figura 3 representa os dados dos respondentes ao questionário final, com relação às questões de escala Likert, agrupadas pela classificação adotada anteriormente para fins didáticos, já que assumimos que são tênues as fronteiras, em alguns casos específicos, de quais elementos são predominantemente unidirecionais e quais não. Nesse sentido, indicamos que dados contextuais da experiência didática empreendida são os que definiram, em última instância, o enquadramento em uma ou em outra categoria.

Em relação ao questionário final, optamos por destacar apenas alguns aspectos gerais que nos chamam atenção. Em primeiro lugar, no que se refere à contribuição da disciplina para a formação profissional, indica-se um ganho substancial em relação à percepção inicial dos estudantes, pois em pergunta semelhante efetuada ao começo do semestre, $46 \%$ dos alunos mostravam-se indecisos em relação a esse aspecto. Ao término do semestre, o número de discentes que identificou a potencialidade de Cálculo Numérico para a formação profissional foi de $96 \%$. Ressaltamos que esse é um dado significativo, considerando especialmente a natureza multicurso da disciplina, na qual encontram-se em sala de aula discentes com diversos focos de interesse e que, comumente, percebem as disciplinas do chamado "ciclo básico" de forma não tão integrada aos seus objetivos profissionais futuros. 
Figura 3 - Resultados do Questionário Final

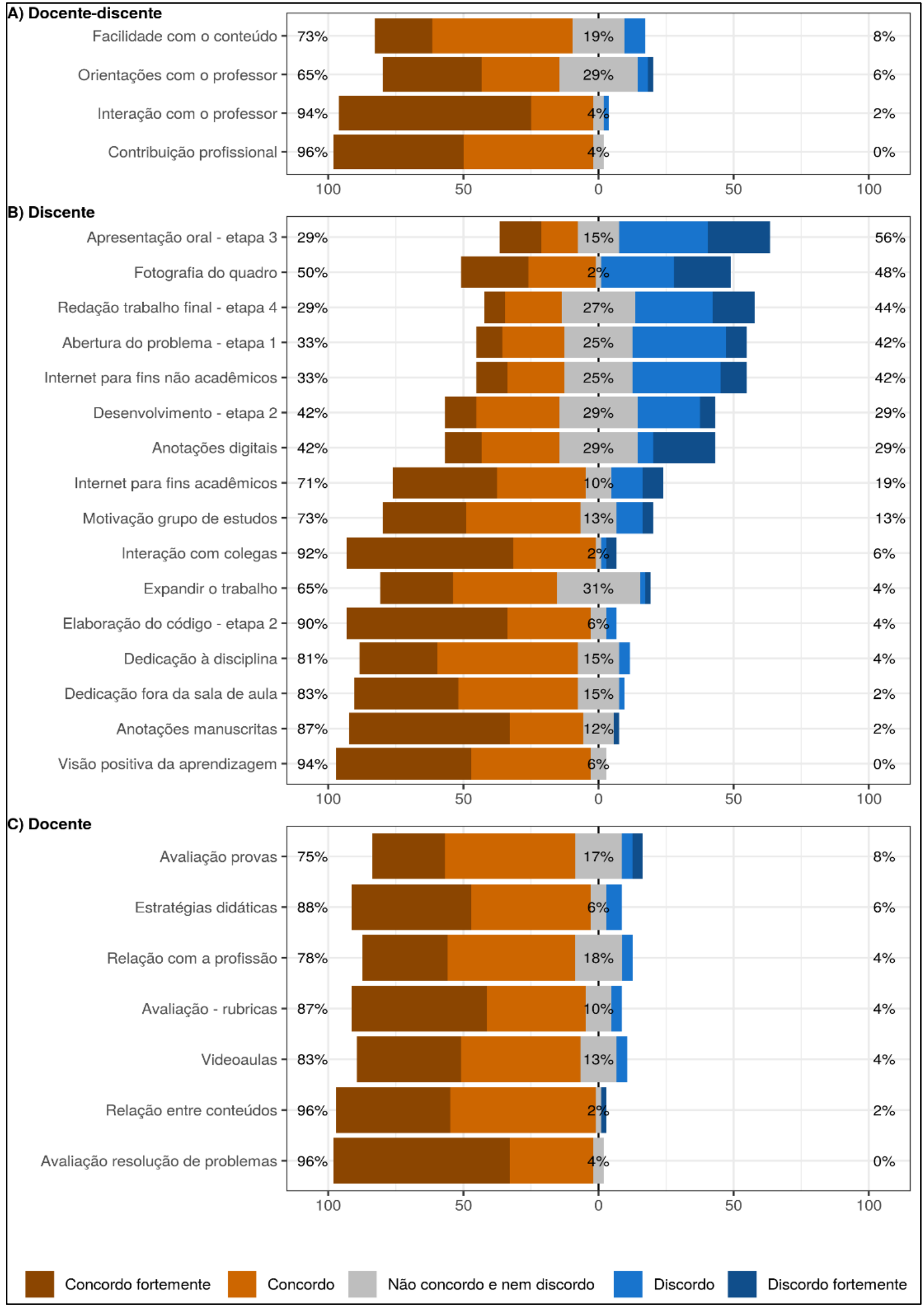

Fonte: Autores, 2020. 
Nesse sentido, as estratégias didáticas e as práticas avaliativas adotadas revelam-se eficientes para impulsionar uma visão favorável do aluno em relação à disciplina de Cálculo Numérico, o que se demonstra especialmente nos resultados altamente favoráveis obtidos em algumas questões, tais como: $94 \%$ na interação com o professor, $92 \%$ na interação com os colegas, $94 \%$ na visão positiva sobre a aprendizagem, $96 \%$ na capacidade de relacionar os conteúdos da disciplina com outros conteúdos e $96 \%$ em relação à avaliação em sala de aula por meio da resolução de problemas. Percebe-se que as práticas adotadas fortaleceram o engajamento interativo, especialmente nas atividades desenvolvidas em sala de aula.

Em relação ao trabalho avaliativo processual (realizado em grupo), por meio da utilização de rubricas, entendidas como dispositivos em que se estabelecem níveis de resultado diferenciados para cada desempenho possível, os alunos são avaliados por quatro etapas: abertura de um problema (etapa 1), desenvolvimento do trabalho e elaboração de um código em linguagem de programação (etapa 2), apresentação oral dos resultados (etapa 3) e entrega de um trabalho escrito desses resultados (etapa 4). As duas primeiras etapas são acompanhadas de orientações realizadas com cada grupo, por meio da tutoria docente fora do horário de aula.

Identifica-se a elaboração do código em linguagem de programação como a etapa considerada mais difícil pelos alunos (90\%). Em relação a esse resultado, nossa hipótese é a de que a grande parte dos estudantes apresenta pouca experiência em programar, pois a maioria apenas cursou "Algoritmos e Programação" em seu percurso formativo até chegar a cursar Cálculo Numérico (com exceção dos estudantes de Engenharia de Computação ou, no caso de estudantes de Licenciatura, podem nem mesmo terem cursado essa disciplina introdutória). Nesse sentido, nas respostas abertas do questionário final, reitera-se a dificuldade em programar como uma das principais barreiras, acrescida da sugestão de ampliar essas oportunidades, mesmo que em Cálculo Numérico já se disponha de algumas aulas voltadas a esse fim, específicas para o desenvolvimento do código.

Também, percebemos uma boa aceitação do uso das rubricas no processo avaliativo (87\%). Esse resultado no questionário final pode ser correlacionado com as respostas dadas no questionário inicial com respeito à pergunta para os discentes que estavam cursando à disciplina pela segunda ou terceira vez, na qual deveriam apontar as razões para suas reprovações anteriores. Como resultado, em relação a essa pergunta, 47,1\% dos alunos apontaram que suas reprovações se deveram ao nervosismo em provas. Assim, a aceitação das rubricas como estratégia avaliativa focada no processo e não no produto, como as provas, tendem a apresentar 
melhor aceitabilidade por parte dos estudantes, os quais indicaram, na pergunta aberta voltada a sugestões para o próximo semestre, a manutenção e ampliação da proposta.

Em relação ao resultado gerado, o qual proporciona aos discentes um processo investigativo com potencial a ser socializado para além do espaço de sala de aula (como, por exemplo, o evento científico organizado pela universidade), identificamos que um número relativamente representativo de estudantes $(31 \%)$ se mostra indeciso quanto à possibilidade de divulgar o trabalho desenvolvido para além da sala de aula.

Em relação às estratégias de registro de conteúdos em aula, os dados demostram que a maioria dos alunos ainda efetua apontamentos manuscritos em caderno (87\%), mas 50\% dos estudantes efetuou registros por meio de fotos no dispositivo móvel dos apontamentos do professor no quadro negro e, ainda, $42 \%$ faz uso de anotações nos próprios dispositivos digitais. Também, chama a atenção o fato de $71 \%$ dos alunos apontarem que utilizam a Internet em sala de aula para fins acadêmicos, em oposição à 33\% que assume utilizá-la para fins não acadêmicos. Esse conjunto de perguntas tem como propósito compreender os novos perfis de alunos (TORI, 2017) e, ao mesmo tempo, promover que eles próprios reflitam sobre os caminhos decisórios tomados durante o seu percurso formativo.

\subsection{RESULTAdOS REFERENTES Às MÉdiAs FINAIS DOS DISCENTES, MOTIVAÇÃo AUTOPERCEBIDA E EMPENHO AUTOPERCEBIDO}

Analisamos a motivação dos discentes considerando as respostas à questão aplicada no início do semestre "De 0 a 10, o quão motivado estou para cursar este componente" versus a percepção do empenho empregado pelo discente através das respostas à questão "De 0 a 10 , como foi seu empenho para cursar este componente" no questionário final. Ainda, analisamos a nota final atribuída aos discentes.

A Tabela 3 apresenta as estatísticas das notas finais dos discentes, considerando o número total dos discentes (total), os aprovados e os desistentes. A nota final média de todos os alunos foi considerada baixa. Temos: média $=6,25$; mediana $=6,88$; Intervalo Interquartil $(\mathrm{IQR})=1,41$; desvio padrão $(\mathrm{DP})=2,36$; amplitude interquartil (ampl. $)=9,25$; coeficiente de variação da média $(\mathrm{CV})=0,38$; variância (var.) $=5,59$. Esse resultado é influenciado fortemente pela nota dos desistentes, com os seguintes resultados: média $=1,3$; mediana $=1,16$ e Intervalo Interquartil $(\mathrm{IQR})=1,54$. O percentual de aprovados, $84 \%(\mathrm{n}=54)$, é considerado alto para os padrões da disciplina, com média $=7,17$; mediana $=7,07$ e Intervalo Interquartil $(\mathrm{IQR})=1,42$. 
Tabela 3 - Estatísticas das notas finais dos discentes

\begin{tabular}{lcccccccccc}
\hline Categorias & $\mathrm{N}$ & Min & Max & Mediana & Média & IQR & DP & Ampl. & CV & Var. \\
\hline Total & 64 & 0,00 & 9,25 & 6,88 & 6,25 & 1,41 & 2,36 & 9,25 & 0,38 & 5,59 \\
Aprovados & 54 & 5,95 & 9,25 & 7,07 & 7,17 & 1,42 & 0,92 & 3,30 & 0,13 & 0,85 \\
Desistentes & 10 & 0,00 & 4,24 & 1,16 & 1,30 & 1,54 & 1,31 & 4,24 & 1,01 & 1,72 \\
\hline
\end{tabular}

Fonte: Autores, 2020.

Cabe salientar que, em relação aos 10 desistentes, havia perfis variados. Tais desistências ocorreram em momentos diferentes do semestre: três desistentes não fizeram quaisquer tipos de avaliação (Engenharia de Energia=2, Engenharia Química=1), outros três (Engenharia de Produção=3) desistiram aproximadamente na metade do semestre, outros dois (Engenharia de Computação=1, Engenharia Química=1) tinham muitas faltas, e, dessa forma, não faziam os trabalhos em grupo através da resolução de problemas em aula e também desistiram na metade do semestre, já os outros dois (Engenharia de Energia=1, Licenciatura em Matemática=1) não fizeram a avaliação de recuperação, desistindo ao final do semestre. Feitos esses esclarecimentos, apontamos que, após sete semestres em que a disciplina vem sendo ministrada pelo mesmo docente, foi a primeira vez em que não houve nenhuma reprovação por nota, somente as dez desistências mencionadas. Estabelecemos essa diferença conceitual para marcar que, em nosso entendimento, somente os consideraríamos "reprovados" e não "desistentes" se esses alunos tivessem se submetido a todo o processo avaliativo proposto e, mesmo assim, não tivessem atingido o parâmetro mínimo previsto pela instituição, ou seja, média 6,0 .

A Tabela 4, a seguir, mostra as estatísticas das notas finais obtidas pelos discentes, agrupadas por curso. Nesta tabela, são considerados apenas os discentes que não desistiram. No total, foram 54 aprovados. Os cursos de Licenciatura em Matemática e Engenharia de Produção apresentaram índices estatísticos muito similares, com médias finais iguais (7,47), amplitudes (3,2 e 3,25, respectivamente) e desvios padrões muito próximos (0,93 e 1,01, respectivamente). Os cursos com maior homogeneidade das notas finais foram Engenharia de Alimentos e Engenharia Química, com coeficientes de variação iguais a 0,1 e 0,9, respectivamente. A análise do curso de Engenharia de Energia não deve ser tomada como referência devido ao número único da amostra $(n=1)$. Cabe observar que os padrões semelhantes ocorreram entre cursos que compartilham dos mesmos turnos de oferta, ou seja, Licenciatura em Matemática e Engenharia de Produção são cursos noturnos e Engenharia de Alimentos e Engenharia Química são cursos ofertados em turno integral. 
Tabela 4 - Estatísticas das notas finais dos discentes aprovados

\begin{tabular}{lcccccccccc}
\hline Curso & $\mathrm{N}$ & Mínimo & Máximo & Mediana & Média & IQR & DP & Ampl. & CV & Var. \\
\hline EA & 5 & 6,09 & 7,62 & 6,34 & 6,61 & 0,68 & 0,64 & 1,54 & 0,10 & 0,41 \\
EC & 4 & 6,21 & 8,70 & 6,64 & 7,05 & 0,97 & 1,14 & 2,49 & 0,16 & 1,29 \\
EE & 1 & 6,01 & 6,01 & 6,01 & 6,01 & 0,00 & NA & 0,00 & NA & NA \\
EP & 18 & 6,00 & 9,20 & 7,18 & 7,47 & 0,56 & 0,22 & 3,25 & 0,13 & 0,87 \\
EQ & 12 & 6,03 & 7,78 & 6,68 & 6,76 & 0,62 & 0,17 & 1,75 & 0,09 & 0,34 \\
LM & 14 & 6,00 & 9,25 & 7,51 & 7,47 & 1,07 & 0,27 & 3,29 & 0,14 & 1,02 \\
\hline
\end{tabular}

Fonte: Autores, 2020.

Finalmente, a Figura 4 mostra em A) o comparativo dos valores autoatribuídos pelos discentes à questão relacionada à motivação inicial (Mot), à percepção do empenho autoatribuído aplicado no decorrer do semestre (Emp) e às notas finais obtidas (NF). É importante ressaltar que este gráfico corresponde somente aos alunos que tiveram registradas as respostas nos dois questionários (inicial e final) e, também, tiveram nota final registrada pelo docente.

Aqui, destaca-se o elevado percentual de alunos que se mostrou extremamente motivado em cursar a disciplina (mais de $60 \%$ atribuíram nota 9 ou 10 para esse quesito). Além disso, cerca de $87 \%$ dos alunos atribuíram nota 8, 9 ou 10 para o empenho aplicado ao final do semestre. Isso demonstra que a percepção do aluno sobre seu engajamento com a disciplina, ainda que limitada somente a essa questão, foi muito elevada. Por outro lado, as notas finais não ficaram tão próximas desses percentuais. Aproximadamente dois terços dos alunos obtiveram notas finais entre 6,0 e 7,5.

O gráfico B) da Figura 4 mostra o boxplot dos valores atribuídos à Motivação (Mot), Empenho (Emp) e Nota Final (NF) por curso ( ${ }^{\circ}$ de alunos: Engenharia de Alimentos $=2$, Engenharia Química $=8$, Engenharia de Produção $=15$ e Licenciatura em Matemática $=13$ ) . Cabe destacar que nenhum aluno do curso de Engenharia de Computação respondeu o questionário inicial ou o questionário final, portanto, não contamos com os dados relacionados a esse curso. Neste gráfico, é possível visualizar facilmente que há homogeneidade na posição das notas finais (a mediana da nota final permanece em um mesmo patamar, em torno de 7,0, para todos os cursos e a amplitude interquartil é similar para os cursos de Engenharia de Alimentos, Engenharia Química e Licenciatura em Matemática). Adicionado a isso, as medianas das notas finais permaneceram inferiores às medianas da motivação inicial autopercebida e do empenho final autopercebido, em todos os cursos. 
Figura 4 - Relação entre notas, motivação e empenho

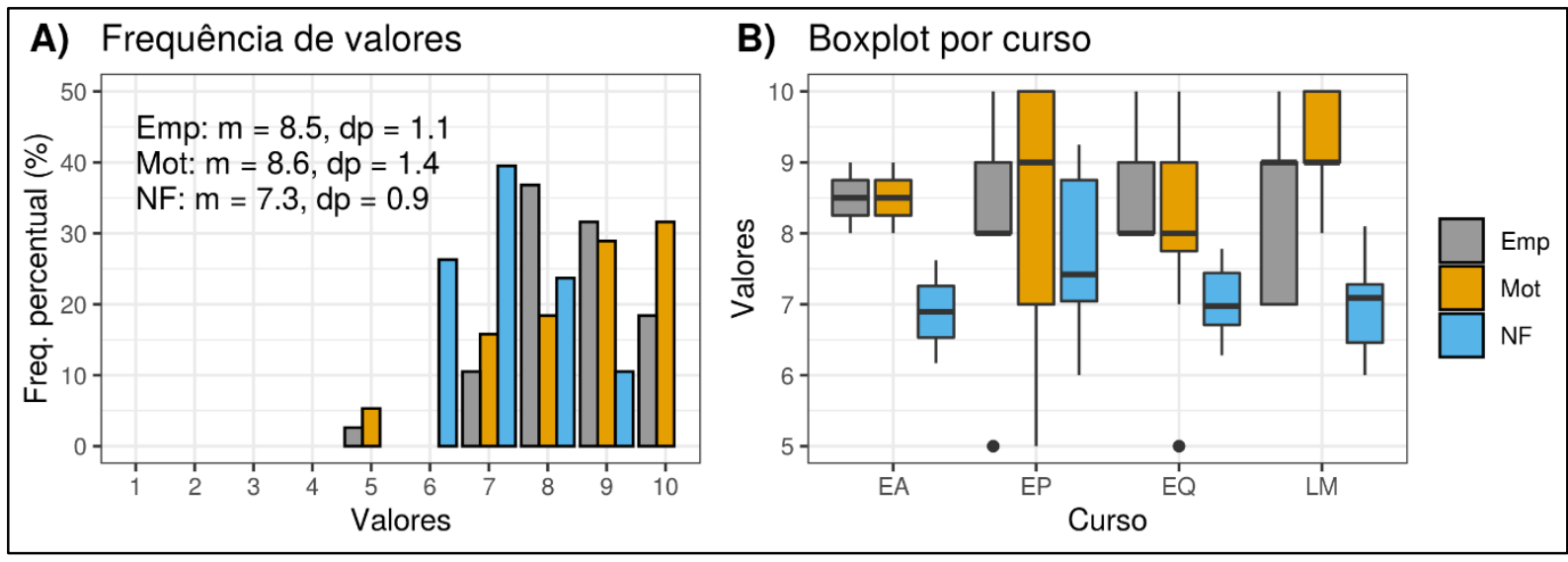

Fonte: Autores, 2020.

Também, é possível notar que há uma grande heterogeneidade nos valores de motivação e empenho (grandes amplitudes entre os quartis inferiores e superiores) para os dois cursos noturnos (Matemática e Engenharia de Produção) e menos para Engenharia de Alimentos (curso com menor número de alunos nos dados analisados) e, seguido dele, Engenharia Química (chama-nos atenção o fato de que ambos são cursos ofertados em turno integral e repete-se aqui a homogeneidade encontrada nos resultados da Tabela 4). Esse espalhamento, corroborado pelos altos valores do desvio padrão (dp), indicam que o contexto de aprendizagem da disciplina pode ser complexo, especialmente para o trabalho docente, no sentido de que parte dos alunos podia não estar tão motivada ao início do semestre e demonstrou empenho ao longo da disciplina e outra parte pode ter reduzido seu empenho ao longo do semestre, mesmo estando mais motivada a princípio. Entretanto, percebe-se, com base nas respostas dos questionários, que a disciplina teve efeitos positivos no bem-estar acadêmico (RODRÍGUEZ et al., 2020), pois o conjunto da proposta didática, seja no que diz respeito às orientações predominantemente unidirecionais (apenas discente ou apenas docente), seja na orientação bidirecional (docentediscente), foi considerado satisfatório para a ampla maioria dos discentes.

\section{CONSIDERAÇÕES FinAIS}

O desafio de promover o engajamento consultivo dos alunos em relação aos tópicos próprios do processo didático pode trazer elementos importantes para a tomada de decisão em relação aos percursos adotados no interior das disciplinas em uma dimensão micro e, também, de forma mais ampla, no âmbito das decisões curriculares mais pertinentes para os cursos de graduação na atualidade.

A percepção discente sobre a dinâmica da sala de aula, sobre o papel de cada um de seus agentes e sobre a utilização de ferramentas que possam ser úteis dentro do ambiente de 
aprendizagem são válidos como ponto de partida para um conjunto de mudanças necessárias no Ensino Superior. É fundamental que essas mudanças se deem de forma situada, tomadas a partir das realidades contextuais existentes e possam contribuir para a permanência e para o bem-estar dos estudantes. Defendemos essa perspectiva porque entendemos que são esses agentes (alunos e professores), no âmbito da própria sala de aula, ou seja, em um movimento bottom-up, quem mais apresentam condições de pensar, planejar e implementar as melhores soluções para os desafios atuais emergentes no campo educacional e não o contrário (top-down), como é comum observar no discurso educacional.

Desenvolver instrumentos confiáveis para validar tais percepções e, ao mesmo tempo, possibilitar um alcance que possa ser estendido a diversas disciplinas (como almejamos no interior do nosso grupo de pesquisa), a fim de poderem ser traçados dados comparativos, não é uma tarefa simples. Identificamos limitações nos instrumentos criados (resultado predominantemente moderado do coeficiente do Alfa de Cronbach). Também, devemos prever maior similaridade no âmbito dos questionamentos efetuados ao início e ao final do semestre (bem como se as perguntas abertas devem ser mantidas, ou, ainda, mesmo mantendo-as, como encorajar os estudantes para que valorizem esse espaço "aberto" como um eixo produtivo do seu engajamento consultivo e com efeitos positivos para o seu processo de aprendizagem).

Também, percebemos a necessidade de formular questionários menos específicos às realidades contingentes de uma ou de outra disciplina (como foi o caso aqui, em que as perguntas eram ajustadas exclusivamente à metodologia didática de um professor). Equacionar o que é de caráter particular e o que pode ser geral para todas as disciplinas é um passo seguinte no âmbito do desenvolvimento de instrumentos apropriados para compreender os cenários das diversas salas de aula, no escopo do projeto de pesquisa em andamento. A maior estabilidade dos instrumentos aplicados também permitirá um acompanhamento longitudinal mais preciso nas propostas didáticas implementadas a partir da pesquisa realizadas.

Como perspectiva futura, também identificamos que é necessário buscar estratégias para incidir sobre o crescente número de estudantes que abandonam as disciplinas antes de concluir todas as etapas avaliativas previstas na instituição foco da nossa pesquisa, pois esse é um cenário de grande desafio tanto do ponto de vista da pesquisa quanto para a docência, o qual temos identificado como um problema complexo a ser compreendido e mitigado. Quais são os caminhos mais produtivos para poder acompanhar e auxiliar esses estudantes do ponto de vista institucional? Que estratégias adotar? Quais as melhores formas de intervenção para evitar o abandono de disciplinas antes do término de um semestre? 
Por fim, ressaltamos, como perspectiva futura, a necessidade de traçarmos caminhos para a disseminação desse tipo de resultado de forma produtiva e ágil aos discentes que colaboram com as pesquisas que se desenvolvem no campo educacional. Não podemos negligenciar que a forma de devolutiva desses resultados a eles é também uma maneira de validar com solidez o próprio engajamento consultivo advogado por nós. Nesse sentido, entendemos que a visualização dos resultados proporcionada por softwares como o R, assim como por outros possíveis softwares livres disponíveis com semelhantes ferramentas, pode contribuir para esse processo, de forma a torná-lo mais relevante a todos.

\section{REFERÊNCIAS}

ACEVEDO, Fernando. Explanatory factors for dropout from higher education in unfavourable socio-academic contexts. Revista Española de Pedagogía, v. 78, n. 276, p. 253-270, 2020. DOI: 10.22550/REP78-2-2020-02.

AFFOLTER, Felicie. Perceptual processes as prerequisites for complex human behaviour. Rehab. Med., v. 3, n. 1, p. 3-9, 1981.

AUBUSSON, Peter; SCHUCK, Sandy. Researching and Learning from our Practices. In: AUBUSSON, Peter.; SCHUCK, Sandy. (Orgs.). Teacher Learning and Development: the mirror maze. Sydney: Australia, Springer, 2008, p.1-12.

BACICH, Lilian; MORAN, José. Metodologias ativas para uma educação inovadora. Porto Alegre: Penso, 2018.

BARROS, Acacio et al. Engajamento interativo no curso de Física I da UFJF. Revista Brasileira de Ensino de Física, v. 26, n. 1, p. 63-69, 2004.

BLASS, Leandro; IRALA, Valesca. O uso da aprendizagem baseada em problemas (PBL) como metodologia de ensino em aulas de Cálculo Numérico. Revista de Educação Matemática, v.17, p.e020035, 7 jul. 2020. DOI: 10.37001/remat25269062v17id360.

BLAXTER; Loraine; HUGHES, Christina; TIGHT, Malcolm. Cómo se hace una investigación. Barcelona: Gedisa, 2005.

BOHN, Hilario. Maneiras inovadoras de ensinar e aprender: a necessidade de (re)construção de conceitos. In: LEFFA, V. (Org.). O professor de línguas estrangeiras: construindo a profissão. Pelotas: Educat, 2001, p.115-124.

BOLS, Alex. The changing nature and importance os student represantation: In: LOWE, Tom; EL HAKIM, Yassein (Orgs.). A handbook for student engagement in Higher Education: Theory into Practice. Londres: Routledge, 2020. p.66-82.

BRYER, Jason; SPEERSCHNEIDER, Kimberly. Likert: Analysis and Visualization Likert Items. R package version 1.3.5., 2016. Disponível em: https://cran.rproject.org/package=likert. Acesso em: 19 ago. 2020. 
BUTLER, Helen et al. The critical friend: facilitating change and wellbeing in school communities. Australia: Acer Press, 2011.

CARBONELL, Jaume. A aventura de inovar: a mudança na escola. Porto Alegre: Artmed, 2002.

CARLESS, David. Exploring learning-oriented assessment processes. Higher Education, v. 69, p.963-976, 2015.

CARLESS, David et al. (Orgs.). Scaling up Assessment for Learning in Higher Education. Singapura: Springer, 2017.

CZAPLINNSKI, Iwona. An Analysis of learning networks of STEM undergraduate students to promote active learning. 2020. 382f. Queesland: Tese de Doutorado (Doutorado em Filosofia) - School of Teacher Education and Leadership. Faculty of Education. Queesland University of Technology, Queesland, 2020.

CORNEJO, José. El self-study de la práctica de los formadores de futuros profesores: bases teóricas, características y modalidades metodológicas. In: RUSSELL, Tom; FUENTEALBA, Rodrigo; HIRMAS, Carolina (Orgs.). Formadores de formadores, descubriendo la propia voz a través del self-study. Santiago do Chile: OEI, 2016, p.25-64.

CRONBACH, Lee. Coefficient alpha and the internal structure of tests. Psychometrika, v. 16. n. 3, p. 297-334, set. 1951.

DALLA VALLE, Luciana et al. Stakeholder perspectives on graphical tools for visualising student assessment and feedback data. Research in Learning Technology, v. 26, jun. 2018. DOI: $10.25304 /$ rlt.v26.1997.

DALMORO, Marlon; VIEIRA, Kelmara. Dilemas na construção de escalas Tipo Likert: o número de itens e a disposição influenciam nos resultados? Revista Gestão Organizacional, v. 6, n. 3, p. 161-174, 2013.

DEVORE, Jay. Probabilidade e Estatística para Engenharia e Ciências. 9 ed. São Paulo: Cengage Learning, 2018.

DORNELLES, Clara. A gente não quer ser tradicional, mas...como é que faz, daí? A inovação curricular e o debate popularizado sobre língua portuguesa e ensino. 2008. 169f. Campinas: Tese (Doutorado em Linguística Aplicada) - Instituto de Estudos da Linguagem, Universidade Estadual de Campinas, 2008.

FEIJÓ, Amanda; VICENTE, Ernesto Fernado; PETRI, Sérgio Murilo. O uso das escalas Likert nas pesquisas de contabilidade. Revista Gestão Organizacional, v. 13, p. 27-41, jan.abr. 2020.

FERRARI, Eduardo Fiore; SÁENZ, Julia Leymonié. Didáctica Práctica para la enseñanza básica, media y superior. 3 ed. Montevidéu: Magro Editores, 2018.

FRANCIS, Julie Elizabeth. Linking Rubrics and Academic Performance: an Engagement Theory Perspective. Journal of University Teaching \& Learning Practice, v. 15, n. 1, 2018. Disponível em: http://ro.uow.edu.au/jutlp/vol15/iss1/3. Acesso em: 18 ago. 2020. 
GREENWOOD, Davydd; LEVIN, Morten. Reconstruindo as relações entre as universidades e a sociedade por meio da pesquisa-ação. In: DENZIN, N.; LINCOLN,Y.(Orgs.).O planejamento da pesquisa qualitativa: teorias e abordagens. Porto Alegre: Artmed, 2006. p.91-114.

HARVEY, Fiona; ANDERSON; James. Empowering students as champions in technology enhanced learning (TEL) to improve digital literacy. In: LOWE, Tom; EL HAKIM, Yassein (Orgs.). A handbook for student engagement in Higher Education: Theory into Practice. Londres: Routledge, 2020. p.187-197.

INGOLD, Tim. The perception of the environment: essays of livelihood, dwelling and skill. Londres/Nova York: Routledge, 2000.

IRALA, Valesca et al. Desempenho estudantil no Ensino Superior: um olhar para as perspectivas discentes e docentes. Revista Educar Mais, v. 4, n. 2, p. 277-293, 2020. Disponível em: http://periodicos.ifsul.edu.br/index.php/educarmais/article/view/1796. Acesso em: 12 out. 2020. DOI: 10.15536/reducarmais.4.2020.277-293.1796.

KASSAMBARA, Alboukadel. Ggpubr: 'ggplot2' Based Publication Ready Plots. R package version 0.1.4, 2017. Disponível em: https://cran.r-project.org/package=ggpubr. Acesso em: 19 ago. 2020.

\section{MATTHIENSEN, Alexandre. Uso do Coeficiente Alfa de Cronbach em Avaliações por} Questionários. Roraima: Embrapa, 2011.

McCOWAN, Tristan. Higher Education for and beyond the Sustainable Development Goals. Londres: Palgrave Macmillan, 2019.

MORAES, Kaluti; HEIDEMANN, Leonardo; ESPINOSA, Tobias. Métodos ativos de ensino podem ser entendidos como recursos para o combate à evasão em cursos de Ciências Exatas? Uma análise pautada nas ideias de Vincent Tinto. Caderno Brasileiro de Ensino de Física, v. 37, n. 2, p. 369-405, ago. 2020. DOI: http://dx.doi.org/10.5007/2175-7941.2020v37n2p369.

MOROSINI, Marília et al. A qualidade da Educação Superior e o complexo exercício de propor indicadores. Revista Brasileira de Educação, v. 21, n.64, p.13-37, 2016.

OLIVEIRA, Andréa; MOURÃO-JÚNIOR, Carlos Alberto. Revista Neuropsicologia Latinoamericana. v. 5, n.1, p. 41-53, 2012.

PICTON, Catherine; KAHU, Ella; NELSON, Karen. 'Hardworking, determined and happy': first-year students' understanding and experience of success, Higher Education Research \& Development, v. 37, n.6, p. 1260-1273, maio 2018. DOI: 10.1080/07294360.2018.1478803.

PROKOP, Tricia; WININGER, Michael. A primer on $\mathrm{R}$ for numerical analysis in educational research. Frontiers in Education, v. 3, n. 80, p. 1-16, 2018, Disponível em:

https://www.frontiersin.org/article/10.3389/feduc.2018.00080. Acesso em: 18 jul. 2020. DOI: 10.3389/feduc.2018.00080. 
R CORE TEAM. R: a language and environment for statistical computing. R Foundation for Statistical Computing, 2019. Disponível em: https://www.R-project.org/. Acesso em: 19 ago. 2020.

RAMOS-RODRÍGUEZ, Elizabeth; MARTÍNEZ, Pablo Flores; PONTE, João Pedro da. An Approach to the Notion of Reflexive Teacher and Its Exemplification on Mathematics Education. Systemic Practice and Action Research, v.30, n.1, p. 85-102, 2017.

RODRÍGUEZ, Susana et al. Success in Mathematics and Academic Wellbeing in PrimarySchool Students. Sustainability, v.12, 3796, 2020. DOI:10.3390/su12093796.

SALVAT, Begoña Gros. Aprendizajes, conexiones y artefactos: la producción colaborativa del conocimiento. Barcelona: Gedisa, 2008.

SANDRETTO, Susan. Tensiones teórico-metodológicas desde una mirada post estructural, en un proyecto de investigación de self-study colaborativo. In: RUSSELL, Tom; FUENTEALBA, Rodrigo \&amp; HIRMAS, Carolina (Orgs.). Formadores de formadores, descubriendo la propia voz a través del self-study. Santiago do Chile: OEI, 2016. p.97-116.

SCHUCK, Sandy; RUSSELL, Tom. Self-Study, Amistad crítica y las complejidades en la formación de profesores. In: RUSSELL, Tom; FUENTEALBA, Rodrigo; HIRMAS, Carolina (Orgs.). Formadores de formadores, descubriendo la propia voz a través del self-study. Santiago do Chile: OEI, 2016. p.117-132.

SOARES et al. Suporte presencial versus suporte virtual no processo de ensinoaprendizagem: uma análise exploratória das percepções discentes. In: SALÃO INTERNACIONAL DE ENSINO, PESQUISA E EXTENSÃO DA UNIPAMPA, 10., 2018, Santana do Livramento. Anais..., Santana do Livramento: UNIPAMPA, 2020. v.10, n.2. Disponível em: https://periodicos.unipampa.edu.br/index.php/SIEPE/article/view/100752. Acesso em: 12 out. 2020.

SOUZA, Ana Cláudia; ALEXANDRE, Neusa Maria Costa; GUIRARDELLO, Edinêis de Brito. Propriedades psicométricas na avaliação de instrumentos: avaliação da confiabilidade e da validade. Epidemiol. Serv. Saúde, Brasília, v. 26, n.3, p.647-657, jul-set. 2017. DOI: 10.5123/S1679-49742017000300022.

STEIL, Carlos Alberto; CARVALHO, Isabel Cristina de Moura (Orgs.). Cultura, percepção e ambiente: diálogos com Tim Ingold. São Paulo: Terceiro Nome, 2012.

TALBERT, Robert. Guia para utilização da aprendizagem invertida no ensino superior. Porto Alegre: Penso, 2019.

THEES, Andréa. “Aprendi no YouTube!”: investigação sobre estudar matemática com videoaulas. 2019. 260f. Rio de Janeiro: Tese (Doutorado em Educação). Universidade Federal do Estado do Rio de Janeiro. 2019.

TINTO, Vincent. Completing college: rethinking institutional action. Chicago: The University of Chicago Press, 2012. 240 p. 
TOBIN, Kenneth. Sociocultural Perspectives on Science Education. In: FRASER, Barry; TOBIN, Kenneth; McROBBIE, C. (Orgs.). Second International Handbook of Science Education. Londres/Nova York: Springer, 2012. p. 3-18.

TORI, Romero. Educação sem distância: as tecnologias interativas na redução das distâncias em ensino e aprendizagem. 2 ed. São Paulo: Artesanato Educacional, 2017.

WICKLAM, Hadley et al. Welcome to the tidyverse. Journal of Open Source Software, v. 4, n.43, 1686, 2019. DOI: 10.21105/joss.01686.

ZANI, Juliana; BUENO, Luzia; DOLZ, Joaquim. A atividade docente e uma proposta de formação para as vídeo-aulas. Linha D’Água, v.33, n.2, p.91-115, 2020. DOI: 10.11606/issn.2236-4242.v33i2p91-115.

Submetido em: 20 de agosto de 2020 .

Aprovado em: 18 de novembro de 2020. 